\title{
INDEPENDENSI DEWAN PENGAWAS SYARIAH SEBAGAI PENGAWAS KEPATUHAN SYARIAH DI LEMBAGA KEUAGAN SYARIAH
}

\author{
R. Suhaimia \\ aMagister Ekonomi Syariah, Faculty of Economics and Business Islam, Universitas Islam Negri \\ Sunan Kalijaga \\ Email: rsuhaimi09@gmail.com
}

\begin{abstract}
Introduction: The sharia supervisory board is an independent institution in a sharia financial institution, the existence of DPS is as a supervisory agency for the implementation of sharia compliance in sharia financial institutions, the appointment of DPS in LKS is through the general meeting of shareholders or RAT which has been approved by he national sharia board (DSN), the sharia supervisory board can also be proposed by the directors and by the highest shareholder of the LKS.

Methods: This study uses a qualitative model that is literature study, qualitative research is a method that emphasizes the deeper aspects of understanding a problem rather than seeing a problem.

Results: The sharia supervisory board as a supervisor in the Islamic financial institution as well as the long arm of the DSN has a role in ensuring the implementation of sharia compliance in LKS, however the appointment and dismissal of DPS is carried by the RUPS or RAT and can also be proposed by some of the strongest directors and shareholders in this institution and the provision of salaries provided by the LKS under supervision indicate that DPS will be less independent, this will raise suspicions that the appointment of DPS is in accordance with interests of big people in the LKS

Conclusion and suggestion: The Sharia supervisory board is an independent institution whitin the LKS and supervises all business activities carried out by the LKS in the field of sharia compliance. The sharia supervisory board (DPS) is an extension of the national sharia council (DSN) which is assigned and authorized to serve all operations and sharia financing products. This research is still less than perfect in this study the data used is only based on secondary data obtained from several available sources such as journals, books and others, further research is expected to also use primary data through direct interviews with data sources which will provide reliable data. more accurate to research.
\end{abstract}

Keywords: The sharia supervisory board, sharia compliance, Islamic financial institutions 


\section{INTRODUCTION}

Perkembangan lembaga keuangan di Indonesia mengalami tren perkembangan yang cukup signifikan, dalam beberapa tahun terahir, perkembangan lembaga keuangan semakin pesat hal tersebut bisa dilihat dengan tersebar luasnya lembaga keuangan di seluruh Indonesia hingga ke pelosok-pelosok negri. Lembaga keuangan di Indonesia adalah semua lembaga yang kegiatannya dalam bidang keuangan, melakukan penghimpunan dan penyaluran dana pada masyarakat dan pembiayaan terhadap perusahaan dan investasi. Perkembangan lembaga keuangan pada saat ini tidak hanya lembaga keuangan konvensional, namun di Indonesia dalam perkembangannya sudah ada lembaga keuangan syariah yang semakin besar dan berkembang hingga saat ini ${ }^{1}$.

Lembaga keuangan syariah (LKS) merupakan salah satu lembaga keuangan yang berada di Indonesia, lembaga keuangan syariah adalah lembaga keuangan yang sesuai dengan prinsip-prinsip syariah, dalam seluruh prakteknya harus sesuai dengan syariah islam. Lebaga keuangan syariah (LKS) memiliki banyak jenis seperti Bank syariah, Asuransi Syariah Koprasi Syariah, Reksadana Syariah dan yang lainnya dan telah menjadi lembaga yang ikut mewarnai Lembaga keuangan di Indonesia, yang berlandaskan dengan nafas Keislamannya. Sejalan dengan perkembangan pertumbuhan lembaga keuangan islam di Indonesia, maka berkembang juga jumlah Dewan Pengawas Syariah di Indonesia sebagai pengawas terhadap masing-masing lembaga keuangan syariah, semakin banyaknya lebaga dan Dewan Pengawas Syariah tersebut akan memunculkan beberapa kebijakan dan ketentuan yang bervariasi terhadap sistem kelola keuangan syariah di masing-masing lembaga².

Dewan pengawas syariah merupakan badan pengawas yang ada dalam setiap lembaga keuangan syariah. Sesuai dengan peraturan pendirian lembaga keuangan syariah bahwa pendirian lembaga keuangan syariah adalah harus ada Dewan Pengawas Syariah (DPS) didalamnya. AAOIFI memberikan pengertian dewan pengawas syariah adalah sebagai lembaga independen serta ahli dalam ilmu fiqih muamalah. Dimana Dewan Pengawas Syariah (DPS) memiliki tugas sebagai pengawas, peninjau dan pengarah dari lembaga keuangan syariah, DPS juga sebagai wakil dari Dewan Syariah Nasional (DSN) MUI pusat di lembaga tersebut.

Keberadaan Dewan Pengawas Syariah (DPS) dalam lembaga keuangan syariah (LKS) merupakan sesuatu yang sangat penting dalam menjamin terjadinya syariah compliance dalam lembaga keuangan yang berbasis syariah. Dalam melakukan pengawasan DPS dan anggota harus memiliki kemampuan beberapa disiplin ilmu yang integral, yaitu ilmu fiqih muamalah, ilmu ekonomi, dan keuangan islam modern, hal

\footnotetext{
1 Idwal.B,Sejarah Perkembangan Lembaga Keuangan Syariah,Institut Agama Islam Negri Bengkulu.

2 Darmawan dan Muhammad Iqbal Fasa,Manajemen Lembaga Keuangan Syariah,Yogyakarta: UNY Press,2020,hlm,76.
} 
tersebut tentunya harus dimiliki oleh seorang Dewan Pengawas Syariah. Kesalahan besar perbankan syari'ah dan lembaga keuangan syariah lainnya saat ini adalah mengangkat Dewan Pengawas Syariah (DPS) karena kharisma dan kepopulerannya di tengah masyarakat, bukan karena keilmuannya di bidang ekonomi dan perbankan syari'ah $^{3}$. Masih banyak anggota Dewan Pengawas Syariah (DPS) yang belum mengerti tentang teknis perbankan dan Lembaga Keuangan Syariah (LKS), apalagi ilmu ekonomi keuangan Islam ${ }^{4}$. Seperti akuntansi, akibatnya pengawasan dan peran-peran strategis lainnya sangat tidak optimal

Dalam praktiknya masih banyak Dewan Pengawas Syariah yang belum bisa membedakan margin dari akad murabahah dengan bunga bank, hal tersebut dikarenakan masih kurangnya pengetahuan tentang keungan syariah, pengangkatan Dewan Pengawas Syariah yang tidak didasarkan pada aspek keilmuan yang dimiliki maka sudah bisa dipastikan, fungsi pengawasan DPS tidak akan optimal (Dian Islamiati 2014). Akibatnya penyimpangan dalam praktek syariah menjadi hal yang mungkin dan sering terjadi. Pengangkatan DPS sendiri adalah melaui RUPS pada lembaga tersebut yang juga bisa di rekomendasikan oleh para direksi lembaga. Serta dapat diberhentikan juga melalui RUPS, di sisi lain, masalah penggajian yang memberi bayaran justru Lembaga Keuangan Syariah tersebut ${ }^{5}$. Tentu saja hal tersebut bisa menimbulkan ketidakprofesionalan dari Dewan Pengawas Syariah.

Berdasarkan uraian dan informasi diatas maka peneliti akan melakukan pendalaman terhadap masalah ke independenan Dewan Pengawas Syariah (DPS) sebagai lembaga pengawas dan mediator lembaga keuangan syariah (LKS) dengan Dewan Syariah Nasional (DSN) dengan judul "Independensi Dewan Pengawas Syariah Sebagai Pengawas Kepatuhan Syariah di Lembaga keuangan syariah".

\section{LITERATURE REVIEW}

\section{Dewan Pengawas Syariah}

Dewan Pengawas Syariah (DPS) adalah lembaga independen yang berada di lembaga keuangan syariah sebagai pengawas terhadap terlaksananya sistem syariah dalam lembaga tersebut. Dewan Pengawas Syariah merupakan pengawas syarih yang mempunyai amanah untuk mengawasi oprasional dan peraktek LKS agar tetap

${ }^{3}$ Farid Hidayat, Alternative Sistem Pengawasan Pada Koperasi Simpan Pinjam Dan Pembiayaan Syariah (KSPPS) Dalam Mewujudkan Shariah Compliance, Mahkamah, Vol.2, No.1, Desember, 2016.

4 Dian Islamiati, Analisa Pelaksanaan Tugas Dewan Pengawas Syariah Dan Implementasinya Di BMT Marwah Kecamatan Tambang, Skripsi Thesis, Universitas Islam Negri Sultan Syarif Kasim Riau, 2014.

${ }^{5}$ Farid Hidayat, Alternative Sistem Pengawasan Pada Koperasi Simpan Pinjam Dan Pembiayaan Syariah (KSPPS) Dalam Mewujudkan Shariah Compliance, Mahkamah, Vol.2, No.1, Desember, 2016. 
konsisten berpegang teguh terhadap prinsip-prinsip syariah ${ }^{6}$. Dewan Pengawas Syariah adalah suatu badan yang bertugas mengawasi pelaksanaan keputusan DSN di lembaga keuangan syariah. DPS diangkat dan diberhentikan di lembaga keuangan syariah melalui RUPS setelah mendapat rekomendasi dari DSN-MUI (Muhammad Firdaus eat al 2007).

Dewan Pengawas Syariah dalam kedudukannya dalam LKS setara dengan Dewan Komisaris, hal tersebut untuk menjaga efiktivitas dari setiap opini yang dikeluarkan oleh Dewan Pengawas Syariah, oleh sebab itu penetapan terhadap DPS dan anggotanya dilakukan dan dipilih dalam Rapat Umum Pemegang Saham, setelah mendapatkan rekomendasi dari Dewan Syarian Nasional (DSN) MUI7. Dewan Pengawas Syariah mengawasi jalannya operasional yang ada dalam lembaga keuangan syariah yang terjadi dalam setiap harinya agar selalu sesuai dengan prinsip-prinsip syariah, sehingga keterjaminan praktek syariah dalam lembaga tersebut dapat terkontrol dan akan memberikan rasa nyaman terhadap nasabah dalam terlaksananya prinsip syariah dalam lembaga.

\section{Indepensi Dewan Pengawas Syariah}

Dalam menentukan kegiatan lembaga sudah memenuhi ketentuan syariah di internal maka lembaga harus memiliki Dewan Pengawas Syariah yang merupakan lembaga independen sebagai pengawas dalam lembaga tersebut. Akhmad Faozan menyatakan bahwa Dewan Pengawas Syariah merupakan fungsi independen yang mempunyai keahlian khusus di bidang fiqih muamalah dan semestinya tidak hanya mampu dalam bidang fiqih semata namun juga ahli dalam bidang lembaga keuangan syariah yang sekaligus juga mampu dalam fiqih muamalah ${ }^{8}$. Dalam menjaga keindependenan seorang DPS adalah salah satunya memiliki pengetahuan yang luas terhadap keilmuan Ekonomi Syariah sehingga segala opini yang dikeluarkan dapat dilihat sebagai suatu opini yang baik, dan dapat dipertanggung jawabkan oleh seorang Dewan Pengawas Syariah. Dalam penelitian Iin Emy Prastiwi dia mengatakan bahwa independensi DPS memiliki pengaruh terhadap kinerja lembaga yang di awasi oleh Dewan Pengawas Syariah tersebut, pengawasan secara langsung dan intens oleh DPS akan memberikan kehati-hatian lembaga dalam proses oprasionalnya untuk selalu sesuai dengan prinsip syariah ${ }^{9}$.

6 M. Taufiq, Optimalisasi Peran Dewan Pengawas Syariah di Lembaga Keuangan Mikro Syariah, Al-Huquq: Journal Of Indonesian Islamic Economic Law, 2 (1), 2020.

7 Muhammad Syafi'I Antonio, Bank Syariah: Dari Teori Ke Praktek,Jakarta: Gema Insani, 2007, hlm,30-31.

8 Winwin Yadiati dan Abdulloh Mubarok, Kualitas Pelaporan Keuangan: Kajian Toritis Dan Empiris,Jakarta:KENCANA,2017,hlm,122.

9 Iin Emy Prastiwi, Pengaruh Independensi Dewan Pengawas Syariah Dalam Mewujudkan Good Corporate Governance Untuk Meningkatkan Kinerja, Jurnal Ilmiah Ekonomi Islam, Vol. 03, No. 01, Maret, 2017. 
Sofyan syafri harahap memberikan pengertian bahwa Dewan Pengawas Syariah merupakan sebuah lembaga independen atau sebagai hakim dalam bidang fiqih muamalah. Dewan Pengawas Syariah (DPS) memiliki kewajiban mengarahkan, me review serta mengawasi aktivitas yang terjadi di lembaga keuangan syariah untuk meyakinkan seluruh pihak bahwa lembaga keuangan syariah tersebut sudah mematuhi aturan dan prinsip syariah yang berlaku ${ }^{10}$. Keberadaan DPS sebagai lembaga independen tentunya diharapkan mampu melakukan pengawasan secara profesional serta independen tanpa ada pengaruh dari pihak lain, sehingga pengawasan dan keterjaminan shariah compliance di dalam lembaga keuangan syariah dapat terjadi.

\section{Lembaga Keuangan Syariah}

Lembaga keuangan syariah merupakan lembaga keuangan yang beroperasi dengan landasan dasar menggunakan prinsip-prinsip syariah dalam menjalankan semua kegiatannya, serta menggunakan akad-akad yang diperbolehkan dalam syariat islam. Lembaga keuangan syariah adalah lembaga keuangan yang mengeluarkan produkproduk keuangan syariah serta mendapatkan izin oprasional sebagai lembaga keuangan syariah ${ }^{11}$. Mardani dalam bukunya menjelaskan Lembaga keuangan syariah adalah perusahaan yang usahanya bergerak dalam bidang jasa keuangan yang berdasarkan atas prinsip syariah. Atau, lembaga keuangan syariah yang menggunakan norma-norma ajaran islam ${ }^{12}$. Lembaga keuangan yang menghilangkan atau meninggalkan unsur-unsur yang dilarang oleh islam, dan menggunakan akad-akad yang ada dalam syariat islam, dalam setiap oprasional yang dilakukan oleh lembaga tersebut.

Dalam lembaga keuangan terbagi menjadi dua bagian yaitu lembaga keuangan bank dan lembaga keuangan nonbank, dalam lembaga keuangan syariah juga terbagi menjadi dua bagian seperti yang ada di lembaga keuangan konvensional. Lembaga keuangan bank adalah badan usaha yang melakukan kegiatan usaha dalam bidang keuangan yaitu menghimpun dana dari masyarakat dan menyalurkan dana kembali pada masyarakat. Lembaga keuangan bank diatur dalam Undang-Undang No. 7 Tahun 1992 tentang perbankan, Undang-Undang No.10 Tahun 1998 tentang perubahan atas Undang-Undang No.7 Tahun 1992 dan Undang-Undang 23 Tahun 1999 tentang Bank Indonesia dan Undang-Undang No.3 Tahun 2004 tentang Bank Indonesia. Dan perbankang syariah diatur dalam Undang-Undang No.21 Tahun 2008. Adapun lembaga keuangan nonbank (LKNB) adalah badan usaha yang melakukan kegiatan dibidang keuangan yang secara langsung atau tidak langsung menghimpun dana dengan

10 Winwin Yadiati dan Abdulloh Mubarok, Kualitas Pelaporan Keuangan: Kajian Toritis Dan Empiris,Jakarta:KENCANA,2017,hlm,122.

11 Ahmad Ifham Solihin,Pedoman Umum Lembaga Keuangan Syariah, Jakarta: PT Gramedia,2010,hlm,51.

12 Mardani,Aspek Hukum Lembaga Keuangan Syariah Di Indonesia,Jakarta: KENCANA,2017,hlm,1-2. 
mengeluarkan surat berharga dan menyalurkannya pada masyarakat guna membiayai investasi perusahaan ${ }^{13}$.

\section{RESEARCH METHODS}

Penelitian ini menggunakan model kualitatif yang bersifat studi pustaka, penelitian kualitatif merupakan sebuah metode yang menekankan pada aspek pemahaman lebih mendalam terhadap suatu masalah daripada melihat sebuah permasalahan. Penelitian kualitatif adalah sebuah penelitian riset yang sifatnya deskripsi, cenderung menggunakan analisis dan lebih menampakkan proses maknanya. Kualitatif jug lebih dikenal dengan penafsiran secara kata-kata dan tidak berbentuk angka-angka. Data yang digunakan dalam penelitian ini adalah data sekunder yang didapat dari berbagai sumber yang sudah ada, data didapatkan dari beberapa sumber seperti penelitian terdahulu, buku dan beberapa web yang menyediakan data penelitian.

Dalam penelitian ini menggunakan teknik analisi data berupa analisis isi (content analysis) dan metode Penelitian deskriptif berkaitan dengan pengumpulan data untuk memberikan gambaran atau penegasan suatu konsep atau gejala, juga menjawab pertanyaan-pertanyaan sehubungan dengan status subyek penelitian pada saat ini, misalnya sikap atau pendapat terhadap individu organisasi dan sebagainya. Hasil penelitian lebih ditekankan pada pemberian gambaran secara obyektif tentang keadaan sebenarnya dari obyek yang diselidiki. Akan tetapi, guna mendapatkan manfaat yang lebih luas, di samping mengungkap fakta, diberikan interpretasi yang cukup kuat.

\section{RESULT AND ANALYSIS}

\section{Dewan Pengawas Syariah (DPS) Di Lembaga Keuangan Syariah}

Dewan Pengawas Syariah adalah sebagai lembaga pengawas independen di lembaga keuangan syariah, dalam lembaga keuangan syariah tidak semua unit usaha memiliki dasar hukum positif yang kuat. Dari semua unit usaha syariah yang ada hanya perbankan syariah atau unit usaha yang berbentuk perseroan terbatas saja yang memiliki dasar hukum positif dalam operasional Dewan Pengawas Syariah meskipun regulasi lanjutan terkait dengan mekanisme pengawasannya belum dirumuskan dengan jelas oleh lembaga yang memiliki kewenangan regulasi sampai saat ini. Ketentuan DPS dalam perbankan syariah diatur dalam Pasal 32 UU No. 21 tahun 2008 tentang Perbankan Syariah dan diperjelas dengan regulasi pendukung seperti Peraturan Bank Indonesia (PBI) nomor 11/33/PBI/2009 tentang Pelaksanaan Good Corporate Governance bagi Bank Umum Syariah dan Unit Usaha Syariah dan dilengkapi pula dengan Surat Edaran Bank Indonesia No 12/13/DPBS tanggal 30 April 2010 tentang 
Pelaksanaan Good Corporate Governance Syariah bagi Bank Umum Syariah dan Unit Usaha Syariah ${ }^{14}$.

Kewajiban Dewan Pengawas Syariah sebagaimana telah diatur dalam keputusan yang telah dikeluarkan oleh Dewan Syariah Nasional (DSN) No. 3 tahun 2000 tentang petunjuk pelaksanaan penetapan anggota Dewan Pengawas Syariah terhadap lembaga keuangan syariah ialah mengawasi kegiatan usaha yang dilakukan oleh lembaga keuangan syariah, supaya sesuai dengan ketentuan dan prinsip-prinsip syariah yang sudah difatwakan oleh Dewan Pengawas Syariah Nasional (DSN) MUI (Rahma Yudi Astuti 2015). Dewan Pengawas Syariah (DPS) memiliki tugas menjaga efektivitas dari lembaga keungan syariah yang diawasi, dari setiap opini yang dikeluarkan oleh Dewan Pengawas Syariah akan mewakili kepatuhan dan kesesuain lembaga yang diawasi DPS, oleh sebab itu penetapan terhadap DPS dan anggotanya dilakukan dan dipilih dalam Rapat Umum Pemegang Saham, setelah mendapatkan rekomendasi dari Dewan Syarian Nasional (DSN) MUI ${ }^{15}$. Di Indonesia, DPS memiliki tiga peran penting dalam mengawasi terlaksananya prinsip syariah, yaitu pertama sebagai konselor dan penasehat bagi direksi dan manajemen, kedua sebagai mediator antara manajemen dengan DSN, ketiga sebagai representatif dari DSN terkait implementasi fatwa DSN ${ }^{16}$.

Keberadaan posisi Dewan Pengawas Syariah (DPS) pada lembaga keuangan syariah dinilai sangat penting dan strategis dalam menilai kebijakan operasional yang ada dalam lembaga tersebut. Seperti melakukan penelaahan produk-produk yang ada dalam lembaga, misalnya produk pembiayaan, tabungan dan yang lainnya ${ }^{17}$. Dewan Pengawas Syariah mempunyai peran penting dalam lembaga terhadap terlaksananya prinsip syariah dalam setiap praktek yang dilakukan oleh LKS, keberadaan DPS juga memiliki fungsi untuk meyakinkan terjaminnya atau terlaksananya oprasional yang sesuai dengan prinsip syariah ${ }^{18}$. Dewan Pengawas Syariah sebagai lembaga independen dalam LKS dalam hal ini sebagai pengawas terhadap terlaksananya shariah compliance dalam LKS tidak boleh dipengaruhi oleh beberapa kepentingan lembaga yang diawasi, DPS sebagai penjamin harus melakukan semua oprasionalnya secara efektif dan independen. Pengangkatan DPS yang dilakukan oleh RUPS atau RAT serta dapat direkomendasikan oleh pihak direksi membuat keberadaan DPS akan dipertanyakan ke

\footnotetext{
${ }^{14}$ Isa Ansori, Problematika Dewan Pengawas Syariah Dan Solusinya, NIZHAM, Vol. 01, No. 01, Januari-Juni, 2013

15 Muhammad Syafi'I Antonio, Bank Syariah: Dari Teori Ke Praktek,Jakarta: Gema Insani, 2007, hlm,30-31.

16 Sepky Mardian, Tingkat Kepatuhan Syariah Di Lembaga Keuangan Syariah, Jurnal Akuntansi dan Keuangan Islam, V0l. 3, No. 1, 2015

17 Ulin Nuha, Optimalisasi Peran Dewan Pengawas Syariah Pada Lembaga Keuangan Mikro Syariah, MALIA: Journal Of Islamic Banking and Finance, Vol. 2, No. 2, Desember, 2018.

18 Didih Muhamad Sudi, Efektivitas Dewan Pengawas Syariah Pada Perbankan Syariah, Disertasi, Universitas Islam Negri Syarif Hidayatullah Jakarta, 2015.
} 
indepenannya terlebih gaji atau fee DPS juga dibayarkan oleh lembaga yang diawasi oleh Dewan Pengawas Syariah tersebut.

\section{Pengawasan DPS Pada LKS}

Dewan Pengawas Syariah adalah lembaga independen yang ada dalam LKS dan sebagai pengawas terhadap seluruh kegiatan usaha yang dilakukan oleh LKS dalam bidang shariah compliance. Dewan Pengawas Syariah (DPS) merupakan kepanjangan tangan dari Dewan Syariah Nasional (DSN) yang mendapat tugas dan wewenang untuk mengawasi seluruh operasional dan produk-produk pembiayaan syariah, Dewan Pengawas Syariah merupakan organ internal dan memiliki kedudukan yang sejajar dengan Dewan Komisaris pada sebuah LKS ${ }^{19}$. Penetapan DPS dilakukan oleh Rapat Umum Pemegang Saham (RUPS) atau Rapat Anggota Tahunan (RAT) setelah anggota DPS mendapatkan rekomendasi dari DSN. DPS dalam pengawasan terhadap LKS menggunakan acuan fatwa-fatwa dari DSN-MUI yang juga sebagai pedoman pelaksanaan shariah compliance terhadap lembaga-lembaga keuangan syariah di Indonesia. FatwaFatwa MUI adalah sebagai acuan bagi DPS untuk menjalankan tugas sebagai lembaga pengawas internal dalam LKS.

Dewan Pengawas Syariah dalam menjalankan peran dan fungsinya sebagai lembaga pengawas independen dalam lembaga keuangan syariah sangat penting dalam rangka mewujudkan terlaksananya shariah compliance, seperti yang terdapat pada keputusan Dewan Pimpinan Pusat MUI tentang susunan pengurus DSN-MUI No. Kep98/MUI/III/2001 diantaranya adalah :

1. Melakukan pengawasan secara periodik pada lembaga keuangan syariah yang berada di bawah pengawasannya.

2. Mengajukan usul-usul pengembangan lembaga keuangan syariah kepada pimpinan lembaga yang bersangkutan dan kepada DSN.

3. Melaporkan perkembangan produk dan operasional lembaga keuangan syariah yang diawasinya kepada DSN sekurang-kurangnya dua kali dalam satu tahun anggaran.

4. Dewan Pengawas Syariah merumuskan permasalahan-permasalahan yang memerlukan pembahasan-pembahasan Dewan Syariah Nasional.

Dewan Pengawas Syariah (DPS) memiliki tugas untuk memberikan nasehat dan saran terhadap para direksi dan para pegawai serta mengawasi seluruh kegiatan dan produk lembaga agar sesuai dengan prinsip syariah. Dewan Pengawas Syariah terdiri dari para pakar syariah untuk mengawasi seluruh aktivitas dan oprasional lembaga

19 Taufik Kurrohman, Peran Dewan Pengawas Syariah Terhadap Syariah Copliance Pada Perbankan Syariah, Jurnal Surya Kencana Satu: Dinamika Masalah Hukum dan Keadilan, Vol. 8, No. 2, Oktober, 2017 
keuangan untuk memastikan kepatuhan terhadap prinsip syariah ${ }^{20}$. Menurut peraturan BI No. 06/24/PBI/2004 tentang bank umum yang melaksanakan kegiatan usaha berbasis syariah dalam pasal 1 ayat 10 menyatakan Dewan Pengawas Syariah merupakan dewan yang melakukan pengawasan terhadap prinsip syariah dalam usaha bank $^{21}$. Pengawasan DPS terhadap LKS yang diawasi menurut peraturan BI tersebut adalah pengawasan yang dilakukan terhadap praktek LKS apakah sesuai atau untuk memastikan kepatuhan syariah pada lembaga keuangan yang diawasi.

\section{Alternatif Pengawasan Pada LKS Dalam Menjaga Independensi DPS}

Pengawasan syariah terhadap lembaga keuangan syariah memiliki nilai urgensi yang sangat penting, karena perkembangan dan aktifitas keuangan syariah begitu cepat dan beragam, hal itu membutuhkan penyikapan yang tepat dan cepat untuk memastikan legalitas kesyariahannya. DSN adalah lembaga pengawasan syariah tertinggi dan juga bertugas mengeluarkan fatwa-fatwa untuk memberikan solusi alternatif akad-akad syariah yang memungkinkan untuk dipraktekkan dalam transaksi yang dilakukan dalam LKS. Tanpa adanya fatwa-fatwa alternatif dari DSN-MUI ekonomi syariah akan ketinggalan dalam segi inovasi dan akan kaku terhadap keadaan ekonomi seperti saat ini. Dewan Pengawas Syriah sebagai pengawas yang ada dilembaga keuangan syariah sekaligus sebagai tangan panjang dari DSN memiliki peranan dalam memastikan terlaksananya shariah compliance di LKS, namun pengangkatan dan pemberhentian DPS yang dilakukan oleh RUPS atau RAT serta bisa juga dilakukan pengusulan oleh beberapa direksi dan pemegang saham terkuat di lemabag tersebut mengindikasikan akan kurang independennya DPS, hal itu akan menimbulkan kecurigaan bahwa pengangkatan DPS sesuai dengan kepentingan orang besar dalam LKS tersebut.

Dalam pemberian honor terhadap DPS juga dipandang kurang efisien, gaji yang dimiliki oleh DPS adalah bersumber dari LKS yang diawasi tentunya hal ini akan menimbulkan ketidak profesionalan dari DPS. Keterikatan gaji dari DPS tersebut akan menimbulkan kecurigaan bahwa pengawasan nantinya akan berimbas terhadap gaji yang akan didapatkan oleh DPS, serta akan menjadikan DPS kurang tegas dalam melakukan pengawasan karena ada sisi ekonomi yang mempengaruhi kinerjanya. Pelaporan hasil pengawasan juga masih kurang, pelaporan DPS dalam pengawasannya tidak hanya kepada DSN tetapi juga kepada lembaga yang berkaitan dengan LKS yang mereka awasi seperti pelaporan juga dilakukan terhadap BI dan dinas Koperasi, sehingga masih dipandang kurang efisien dalam proses pelaporan hasil pengawasan yang dilakukan oleh para DPS.

\footnotetext{
20 Farid Hidayat, Alternative Sistem Pengawasan Pada Koperasi Simpan Pinjam Dan Pembiayaan Syariah (KSPPS) Dalam Mewujudkan Shariah Compliance, Mahkamah, Vol.2, No.1, Desember, 2016.

21 Ari Kristin Prasetyoningrum, Analisis Pengaruh Independensi dan Profesionalisme Dewan Pengawas Syariah Terhadap Kinerja Bank Perkreditan Rakyat Syariah di Jawa Timur, Aset, Vol. 12, No. 1, Maret, 2010.
} 
Oleh sebab itu diperlukan beberapa alternatif untuk menjaga independensi DPS dalam melaksanakan tugasnya sebagai pengawas syariah di setiap LKS, dalam hal ini berupa sistem yang akan memberikan ruang terhadap DPS agar mampu menjadi lembaga independen. Dalam beberapa penelitian ada beberapa alternatif yang sudah ditawarkan, hemat penulis ada beberapa hal yang harus diperhatikan untuk menjaga keindependenan DPS beberapa alternatif yang perlu dilakukan menurut hemat penulis adalah sebagai berikut :

1. Perlunya suatu badan satu atap yang membawahi Dewan Pengawas Syariah, dimana badan tersebut bertugas mengawasi dan memberikan arahan

2. Pembentukan Badan yang membawahi DPS dibentuk oleh pemerintah

3. Pemberian gaji badan dan DPS adalah dari pemerintah

4. Pengangkatan DPS dilakukan oleh Dewan Syariah Nasional (DSN) MUI

5. Pemberhentian DPS dilakukan oleh DSN dan dapat diusulkan oleh LKS

6. Laporan pertanggung jawaban DPS dilakukan kepada badan tersebut tidak lagi kepada isntasi lain yang sepeti sekarang.

\section{CONCLUSION}

Dewan Pengawas Syariah adalah lembaga independen yang ada dalam LKS dan sebagai pengawas terhadap seluruh kegiatan usaha yang dilakukan oleh LKS dalam bidang shariah compliance. Dewan Pengawas Syariah (DPS) merupakan kepanjangan tangan dari Dewan Syariah Nasional (DSN) yang mendapat tugas dan wewenang untuk mengawasi seluruh oprasional dan produk-produk pembiayaan syariah, Dewan Pengawas Syariah merupakan organ internal dan memiliki kedudukan yang sejajar dengan Dewan Komisaris pada sebuah LKS. Di Indonesia, DPS memiliki tiga peran penting dalam mengawasi terlaksananya prinsip syariah, yaitu pertama sebagai konselor dan penasehat bagi direksi dan manajemen, kedua sebagai mediator antara manajemen dengan DSN, ketiga sebagai representatif dari DSN terkait implementasi fatwa DSN.

Penetapan DPS dilakukan oleh Rapat Umum Pemegang Saham (RUPS) atau Rapat Anggota Tahunan (RAT) setelah anggota DPS mendapatkan rekomendasi dari DSN. DPS dalam pengawasan terhadap LKS menggunakan acuan fatwa-fatwa dari DSN-MUI yang juga sebagai pedoman pelaksanaan shariah compliance terhadap lembaga-lembaga keuangan syariah di Indonesia. namun pengangkatan dan pemberhentian DPS yang dilakukan oleh RUPS atau RAT serta bisa juga dilakukan pengusulan oleh beberapa direksi dan pemegang saham terkuat di lemabag tersebut mengindikasikan akan kurang independennya DPS, serta pemberian gaji yang juga berasal dari LKS yang diawasi, hal itu akan menimbulkan kecurigaan bahwa pengangkatan DPS sesuai dengan kepentingan orang besar dalam LKS tersebut. 
Oleh sebab itu diperlukan beberapa alternatif untuk menjaga independensi DPS dalam melaksanakan tugasnya sebagai pengawas syariah, beberapa alternatif yang perlu dilakukan adalah sebagai berikut, Perlunya suatu badan satu atap yang membawahi Dewan Pengawas Syariah, dimana badan tersebut bertugas mengawasi dan memberikan arahan yang dibuat oleh pemerintah, yang nantinya gajinya juga berasal dari pemerintah, pelaporan DPS juga akan langsung kepada badan tersebut. pengangkatan DPS dan pemberhentian DPS dilakukan oleh DSN sebagai lembaga pengawas syariah tertinggi.

\section{REFERENCES}

Ahmad Ifham Solihin,Pedoman Umum Lembaga Keuangan Syariah, Jakarta: PT Gramedia,2010,hlm,51.

Darmawan dan Muhammad Iqbal Fasa,Manajemen Lembaga Keuangan Syariah,Yogyakarta: UNY Press,2020,hlm,76.

Muhammad Syafi'I Antonio, Bank Syariah: Dari Teori Ke Praktek,Jakarta: Gema Insani, 2007, hlm,30-31.

Mardani,Aspek Hukum Lembaga Keuangan Syariah Di Indonesia,Jakarta: KENCANA,2017,hlm,1-2.

Winwin Yadiati dan Abdulloh Mubarok, Kualitas Pelaporan Keuangan: Kajian Toritis Dan Empiris,Jakarta:KENCANA,2017,hlm,122.

Ari Kristin Prasetyoningrum, Analisis Pengaruh Independensi dan Profesionalisme Dewan Pengawas Syariah Terhadap Kinerja Bank Perkreditan Rakyat Syariah di Jawa Timur, Aset, Vol. 12, No. 1, Maret, 2010.

Farid Hidayat, Alternative Sistem Pengawasan Pada Koperasi Simpan Pinjam Dan Pembiayaan Syariah (KSPPS) Dalam Mewujudkan Shariah Compliance, Mahkamah, Vol.2, No.1, Desember, 2016.

Isa Ansori, Problematika Dewan Pengawas Syariah Dan Solusinya, NIZHAM, Vol. 01, No. 01, Januari-Juni, 2013.

Idwal.B,Sejarah Perkembangan Lembaga Keuangan Syariah,Institut Agama Islam Negri Bengkulu.

Iin Emy Prastiwi, Pengaruh Independensi Dewan Pengawas Syariah Dalam Mewujudkan Good Corporate Governance Untuk Meningkatkan Kinerja, Jurnal Ilmiah Ekonomi Islam, Vol. 03, No. 01, Maret, 2017.

M. Taufiq, Optimalisasi Peran Dewan Pengawas Syariah di Lembaga Keuangan Mikro Syariah, Al-Huquq: Journal Of Indonesian Islamic Economic Law, 2 (1), 2020.

Rahma Yudi Astuti, Analisa Kinerja Dewan Pengawas Syariah di Bank Syariah, AlTijarah, Vol. 1, No. 2, Desember, 2015. 
Sepky Mardian, Tingkat Kepatuhan Syariah Di Lembaga Keuangan Syariah, Jurnal Akuntansi dan Keuangan Islam, V0l. 3, No. 1, 2015

Taufik Kurrohman, Peran Dewan Pengawas Syariah Terhadap Syariah Copliance Pada Perbankan Syariah, Jurnal Surya Kencana Satu: Dinamika Masalah Hukum dan Keadilan, Vol. 8, No. 2, Oktober, 2017.

Ulin Nuha, Optimalisasi Peran Dewan Pengawas Syariah Pada Lembaga Keuangan Mikro Syariah, MALIA: Journal Of Islamic Banking and Finance, Vol. 2, No. 2, Desember, 2018.

Didih Muhamad Sudi, Efektivitas Dewan Pengawas Syariah Pada Perbankan Syariah, Disertasi, Universitas Islam Negri Syarif Hidayatullah Jakarta, 2015.

Dian Islamiati, Analisa Pelaksanaan Tugas Dewan Pengawas Syariah Dan Implementasinya Di BMT Marwah Kecamatan Tambang, Skripsi Thesis, Universitas Islam Negri Sultan Syarif Kasim Riau, 2014. 